Evolution of Homosexuality in the Human Males: Improved MixedTeam Performance Hypothesis

Ronald C.H. Flipphi ${ }^{1}$ and Maarten van Ginkel $^{2}$

1. Independent Scholar, Den Haag, the Netherlands

2. Independent Scholar, Amsterdam, the Netherlands. ORCID 0000-0002-9131-6873

Updated December 18, 2021 


\section{Evolution of Homosexuality in the Human Male: Improved Mixed- Team Performance Hypothesis}

Male homosexual preference (MHP) is present in many human societies, making up a small but significant cohort. Because homosexual mate preferences are associated with lower fecundity, many evolutionary explanations have been advanced to account for the persistence of this trait. After reviewing a number of these hypotheses and finding room for additional explanations, we propose a new hypothesis that depends on the observed greater empathy and reduced hostility of men who express MHP. This gives them a central role in the performance of groups or teams (all male and mixed) where cooperation and intra-team coherence are at a premium. In this view, teams that contain men with MHP will outcompete teams without such men, other variables being similar. The links between personality traits and team performance do not require homosexual activity within the group. The hypothesis is supported by observations of the personality traits associated with MHP, such as increased agreeableness, which is linked to the literature on team cohesion and performance in sports and other kinds of teams and groups. This novel hypothesis could be examined through direct study of team performance. The proposed hypothesis may also have relevance to better performance among the diverse teams whose efficient performance is so important in modern society.

Public significance statement: We offer a novel proposal to account for the stable but low prevalence of male homosexual preference across cultures. The greater agreeableness associated with male homosexuality might enhance the performance of teams that include homosexual men, compensating for the reduced fecundity of homosexual men. This proposal adds to previous ideas about prosociality, and we offer testable hypotheses of our proposal.

Keywords: evolution; homosexuality; reproductive success; agreeableness; cooperation; team performance; fecundity 


\section{Introduction}

The relatively high prevalence of male homosexual preference (MHP; a.k.a. gay men, male homosexuality) in the human male population has long been regarded an enigma (Camperio Ciani, Corna \& Capiluppi, 2004; Barthes, Godelle \& Raymond, 2013; O'Keefe, O'Keefe \& Hodes, 2018). Standard evolutionary theory states that the "aim" of living organisms is to pass on as many copies of their genes as possible to their next generation progeny. However, gay men have no, or substantially less, sexual intercourse with women, and so either no or fewer progeny. An Australian study reported that although about $50 \%$ of gay men had experienced sex with at least one woman, the frequency of opposite-sex intercourse was much lower than in the heterosexual population (Richters et al., 2014). This negative impact on individual reproductive success raises the question whether there is an adaptive value or compensatory mechanism that maintains the frequency of the gay population at relatively low, but stable and universal levels.

We restrict ourselves to MHP as distinct from female homosexuality, which may differ in many particularities. We address evolutionary explanations of why MHP is so relatively common, focusing on evolutionary hypotheses and not on mediating mechanisms.

\section{Prevalence}

Male same-sex behavior has been observed throughout most of recorded history, in almost all cultures, and across many social groups (Tskhay \& Rule, 2016). For example, male same-sex behavior between experienced and novice warriors in Samurai and Spartan cultures is well documented by Adriaens and De Block (2006), who propose it to be a result of the requirement for strong alliances during active combat, which they 
think gay sex among members helps to enable. Male same-sex behavior is also observed in our closest non-human relatives, having been documented in more than 50 primate species (Kirkpatrick, 2000; Vasey, 2016) and seems to have a long evolutionary history among primates (Adriaens \& De Block, 2006; Bailey et al., 2016).

In a wide sample of global studies, the percentage of men who self-report MHP ranges between 0.5\% and 15\% (Barthes et al., 2015; Camperio Ciani, Battaglia \& Zanzotto, 2015). Combined analysis of three studies in the UK, France and the USA showed a range of 1.1-7.1\% (2003). Such figures are likely underestimates because MHP continues to be viewed negatively in many cultures. A working range of $2-5 \%$ for MHP probably reflects the situation reasonably accurately in most cultures, making up a small but significant cohort in society (Rahman \& Wilson, 2003; Bailey et al., 2016).

\section{Genetics}

There is evidence that sexual preference is at least partly based on genes (Bao \& Swaab, 2010). In 52\% of male monozygotic cotwins in homosexual male probands, both were either homosexual or bisexual (Bailey \& Pillard, 1991). Chaladze (2016) finds concordance for MHP within monozygotic twins to be $20 \%$. Another study calculates that the genetic component accounts for 45-50\% of MHP (Camperio Ciani et al., 2015). Differences between studies may point to additional epigenetic effects operating over and above chromosomal genetic effects (Rice, Friberg \& Gavrilets, 2012; Ngun \& Vilain, 2014). In their review of several studies, Rahman and Wilson (2003) conclude that $50-60 \%$ of the variance in sexual orientation is due to genetic factors. A more recent study of almost half a million individuals established a heritability range of 8$25 \%$, although it was not able to determine conclusively the relative contributions of nature and nurture (Ganna et al., 2019). 
Several older studies strongly indicate that the X-chromosome is involved in inheritance of MHP. Hamer, Hu, Magnuson, Hu and Pattatucci (1993) first reported, that the Xq28 region on the long arm of the $\mathrm{X}$-chromosome was responsible for at least part of MHP. In a meta-analysis of four studies, Hamer (1999) later confirmed the decisive role of the $\mathrm{Xq} 28$ chromosomal region. A subsequent study found three additional regions linked with MHP (Mustanski et al., 2005). More recently, in a relatively large study, Xq28 was again implicated in MHP (Sanders et al., 2015), and in a separate study a further three new linked regions were identified (Sanders et al., 2017).

It is at least plausible that heterosexual, heterozygous carriers of the MHP allele(s) experience some reproductive advantage, which enables them to pass on the allele(s) through heterosexual intercourse, resulting in a percentage of homozygous MHP men above the level that would be expected from alleles that are neutral or disadvantageous in heterozygotes. Most of the present theories about MHP include proposed explanations for such compensatory mechanisms. However, only one of the present theories asks whether the higher-than-expected frequency of MHP is the result not of indirect compensatory, carrier or inclusive fitness effects, but rather due to direct positive advantages of MHP in communities, which promote its transmission to the next generation. That theory is the sociosexuality hypothesis by Barron and Hare (2020).

\section{Sociosexuality hypothesis}

This recent hypothesis proposes that the process of evolutionary self-domestication in humans selected for reduced reactive aggression, ease of social integration (prosocial behavior), within-group tolerance and social affiliation (Barron \& Hare, 2020). Much earlier, Kirkpatrick (2000) also emphasized the importance of social aspects in alliance formation involving same-sex partners. As primate societies became more complex, 
sexual behaviors gained relevance in social interactions over and above their fundamental role in reproduction, providing social benefits around social bonding. Human societies represent an advanced example of sexual behavior having social functions, such as promoting social bonds, affiliations and alliances. Prosocial individuals would have benefitted from being members of cooperative groups. Barron and Hare (2020) state that this would equally be the case for homosexual and heterosexual individuals alike, with homosexuals no more prosocial than heterosexuals. That equality being the case, if the reproductive fitness of males exhibiting MHP is lower than that of heterosexual males, why are people with MHP still present in modern society? The authors propose that their sociosexual hypothesis is testable in terms of within-group cohesion and cooperative tasks, and we return to that suggestion near the end of this paper.

\section{A new hypothesis}

Many of the proposed evolutionary hypotheses summarized below can indeed explain part of MHP in human populations. But these may not add up to explain all observed cases (Bailey et al., 2016). Therefore, additional explanations remain possible. Our proposed hypothesis is therefore not presented because it is in any way better than the others, but in order to explain remaining cases not covered by existing hypotheses.

Our hypothesis of improved mixed-team performance shows credible positive selection for MHP during evolution. We build on Barron and Hare's sociosexual hypothesis (2020), underpinning it with linked instrumental personality features. Then we expand the enhanced social role of MHP individuals to present the benefits in enhancing cooperation among individuals, resulting in improved mixed-team team performance. Finally, we propose how this hypothesis can be tested. But first we review the other existing hypothesis. 


\section{Theories for the persistence of male homosexuality in populations}

Theories to address the presence of MHP in human populations are often grouped in categories, although authors sometimes differ on grouping criteria. Therefore, here we present all well-described published hypotheses individually to do each justice, although some overlap may be noted.

\section{Balanced polymorphism}

Miller (1999) posits that male individuals who carry many alleles for traits with feminizing effects are gay, while individuals with fewer of these alleles, in the presence of other specific "heterosexual" alleles are not gay but are more attractive, charming, kind, sensitive, empathetic, tender-minded, committed, and loyal. This makes them better fathers and thus more attractive heterosexual mates to women. The genes and alleles involved are propagated through their heterosexual, heterozygous carriers.

\section{Overdominance}

The overdominance hypothesis is one of several balancing-selection hypotheses. In this case, heterosexual females create increased progeny in the parental lineage of homosexual individuals, which counteracts the reduced reproduction by the gay individuals themselves (Camperio Ciani \& Pellizzari, 2012). Females heterozygous for the putative MHP gene(s) would show increased fecundity, while male homozygous individuals exhibit MHP. Females heterozygous for the same allele(s) are heterosexual and have greater reproductive fitness than heterosexual females homozygous for nongay allele(s), and thus maintain the gay allele(s) in the population (Savolainen \& Hodgson, 2016). 
In their 2015 paper, Camperio-Ciani et al. analyze models of overdominance that predict fecundity enrichments, which are not actually observed in nature. Thus full confirmation of the hypothesis is still being sought.

\section{Hypergyny}

Like balancing polymorphism and overdominance, the hypergyny hypothesis supposes that both increased female fertility and MHP are pleiotropic results of the same allele(s) (Barthes et al., 2013). Increased female fertility is associated with female attractiveness if this attractiveness leads to hypergyny; that is, women of above-average attractiveness "marry up" in socially stratified societies. Under such conditions, they and their children will have access to more resources, the defining characteristic of "higher social classes", leading to greater reproduction and survival of the children. Genetic factors underlying female attractiveness could thus have associated negative pleiotropic effects on fitness that would benefit from higher female fertility. Homosexuality, with its lower reproductive success, might be such a pleiotropic cost. The progeny of hypergyny would include an above average number of gay sons; heterosexual, heterozygous sons would produce more gay grandchildren.

Although doubts have been raised regarding the validity of this hypothesis at various levels (VanderLaan et al. 2014), in a subsequent study of 107 societies, the original authors consider the hypergyny hypothesis further confirmed (Barthes, Crochet \& Raymond, 2015). The hypergyny hypothesis thus appears to remain valid.

\section{Sexually antagonistic factor (with enhanced fecundity of female maternal relatives)}

This too is an example of balancing-selection hypotheses (Camperio Ciani \& Pellizzari, 2012), in which reduced fitness of MHP males is balanced by enhanced fecundity of 
maternal relatives. Camperio Ciani et al. (2004) report that in a study of more than 4600 men and their relatives, mothers and aunts in the maternal line of homosexual individuals are more fecund than those in the maternal line of heterosexual men. This difference in progeny size was not observed in the paternal lineages of heterosexuals and homosexuals. The sexually antagonistic factor hypothesis proposes that the sexes respond differently to the MHP-related allele(s). In men these alleles result in MHP and hence reduce or eliminate reproduction. In women, MHP alleles increase attractiveness, making them more attractive as mates and leading to greater fecundity. Very large studies have confirmed increased fecundity in the maternal line of homosexuals, compared to paternal lineages (Camperio Ciani \& Pellizzari, 2012) and the effect was confirmed independently by Rahman et al. (2009) with a UK sample. The greater fecundity would also result in more homosexual sons, but this should not cancel out the overall increased progeny.

Camperio Ciani, Cermelli and Zanzotto (2008) showed that a one-locus model could not account for the observations explained in the sexually antagonistic factor hypothesis, where female fecundity and MHP are both involved. They conclude that at least two loci are involved, at least one of which must be located on the X-chromosome. The two-locus model, where one locus on the X chromosome confers increased fecundity in females and increases the probability of MHP in male carriers, as outlined by Camperio Ciani and Pellizzari (2012), coincides with various other genetic studies, including comparative model analyses (Camperio Ciani et al., 2015). In a study of 358,426 participants, aggregate genome-wide single-nucleotide polymorphism (SNP) effects (i.e., alleles) in MHP individuals were correlated with genetic effects in individuals, who only had sex with opposite-sex partners, increasing their number of opposite-sex sexual partners. Such increased mating advantages for opposite-sex 
individuals having alleles associated with MHP could explain the continued presence of MHP in human populations (Zietsch et al., 2021).

Camperio Ciani et al. (2004) state that the sexually antagonistic factor hypothesis explains only part of the presence of MHP in society, and that it is distinct from the fraternal birth order hypothesis (Camperio Ciani \& Pellizzari, 2012), discussed below.

\section{Kin selection}

More than four decades ago, Wilson (1975) proposed that homosexual men would be more supportive to their families, thus contributing indirectly to increasing the family's fecundity and in the process offsetting their own reduced reproductive capacity. Some of the increased progeny of siblings would be heterozygous carriers of the MHP-related genes, thus increasing the gay person's inclusive fitness (the sum of his own offspring and the offspring of his heterosexual kin, devalued by the degree of relatedness). If gay individuals are altruistic to kin, who subsequently have more progeny as a result, then this may indeed increase the frequency of gay genotypes within populations (Abild, VanderLaan \& Vasey, 2014). This could help to increase fecundity of the family in stressful conditions, by increasing its resilience to stress through the enhanced emotional qualities of homosexual individuals. Enhanced fecundity would then propagate MHP alleles through heterosexual liaisons of heterozygous family members (O’Keefe et al., 2018).

There is, however, little if any evidence across cultures that homosexual men support family members any more than heterosexual relatives (Rahman \& Hull, 2005; Adriaens \& De Block, 2006; Abild et al., 2014). Kin selection for MHP may therefore well occur in some cultures, but possibly not in most, which requires further study 
(Bobrow \& Bailey, 2001; Camperio Ciani \& Pellizzari, 2012; Camperio Ciani et al., 2015).

\section{Fraternal Birth Order Effect}

This hypothesis is based on the observation that the probability of a son exhibiting MHP increases with the number of previously born sons (Blanchard \& Bogaert, 1996;

Camperio Ciani \& Pellizzari, 2012), a phenomenon reported in many studies in several different cultures (Camperio Ciani et al., 2004). Blanchard and Bogaert (1996) propose that the effect occurs as a result of antibody buildup in mothers from carrying male fetuses. The mother's body would thus be able to "remember" her earlier sons in terms of the increasing amount of "anti-male" antibodies these pregnancies had generated. Eventually these accumulated antibodies would affect the sexual development of the fetal brain in a subsequent male (Camperio Ciani \& Pellizzari, 2012). For each older brother the youngest brother would have a 33\% increased chance of exhibiting MHP (Blanchard \& Bogaert, 1996; Blanchard, 2001). A meta-analysis of 26 studies involving about 20,000 individuals found a statistically significant effect of fraternal birth order (Blanchard, 2018).

Blanchard and Bogaert (2004) calculate that $28.6 \%$ of homosexual men can attribute their sexual orientation to fraternal birth order. Therefore, this hypothesis alone cannot explain the full observed frequency of MHP, nor its consistency (Camperio Ciani \& Pellizzari, 2012; Gavrilets, Friberg \& Rice, 2018). A group of authors that included the original proposers of the hypothesis calculated that only about one homosexual person in seven is gay due to the fraternal birth order effect hypothesis, leaving six out of seven cases to be explained otherwise (Cantor, Blanchard, Paterson \& Bogaert, 2002). 
Additional models predict that fraternal birth order does not result in the necessary full frequency of MHP (Camperio Ciani \& Pellizzari, 2012). Some studies were not able to establish any effect of fraternal birth order on MHP, despite sizable samples (Currin, Gibson \& Hubach, 2015; Kishida \& Rahman, 2015). The relative contribution of genetic and non-genetic factors is unknown. Recently, however, a Ylinked protein and male protein-specific antibodies have been identified that would enable the proposed mechanism, strengthening its claim to significantly contribute to MHP presence (Bogaert et al., 2018).

\section{Improved Mixed-Team Performance}

Because the hypotheses reviewed above do not explain all cases of MHP, we propose the improved mixed-team performance hypothesis as an additional theory.

Men with MHP also show above-average cooperation and prosocial behavior, alluded to in some existing hypotheses for MHP, in particular the sociosexual hypothesis. We propose extending those benefits beyond same-sex relationships and (extended) family context into the entire social group. In several cases, these cooperation-enhancing social traits may extend to groups or teams (which, in all subsequent references, should be taken to include all-male and mixed male-female teams) of mixed heterosexual and male homosexual preferences, where they result in significantly higher levels of task performance. We will need to show that this extension makes evolutionary sense; how improved performance of mixed teams, here defined as containing heterosexual and male homosexual individuals, also increases inclusive fitness for the team's homosexual members. Like some of the hypotheses described above, we propose that it allows genetic and other enabling mechanisms underpinning the expression of MHP to be transmitted through heterosexual and heterozygous members of the team, which 
performs better than teams with fewer members exhibiting MHP.

Our hypothesis can help to explain some of the remaining MHP prevalence that other hypotheses cannot account for.

\section{Aggression, hostility and empathy}

In surveys of various cultures, male individuals who identify as homosexual express lower levels of aggression and hostility and higher levels of empathy than heterosexuals (Gladue \& Bailey, 1995; Salais \& Fischer, 1995; Harris, 2004; Sergeant, Dickins, Davies \& Griffiths, 2006; O'Keefe et al., 2018). Men who show MHP were on average more altruistic, cooperative, empathetic, kind, and sensitive (O’Keefe et al., 2018). Statistically significantly higher levels of empathy and lower levels of aggression were reported by male homosexuals than by heterosexuals (Sergeant et al., 2006). Among homosexual males, empathy was more negatively correlated with aggression than among heterosexual men. Empathy explained a greater amount of variance in aggression in homosexual males compared to heterosexual males. This suggests that the mitigation effect of empathy on aggression is higher in male homosexuals than in male heterosexuals. On average, homosexual men are less aggressive and more agreeable, pro-social and eager to help in social situations, than heterosexuals. Personality studies using the Big Five Personality Inventory (or Five-Factor Model (FFM)), which is claimed to be universal, capture this type of behavior under the term "agreeableness" (Costa Jr \& McCrae, 1988). In a study of 113,749 men predominantly in the United Kingdom, the United States of America, Canada, Australia, New Zealand, and Western Europe, homosexual men score significantly higher on agreeableness than heterosexual men (Lippa, 2008). Agreeableness among 5451 homosexual men in New Zealand was statistically higher than among heterosexual men (Greaves, Barlow, Huang, Stronge \& Sibley, 2017). In a particularly large recent systematic review and meta-analysis of 21 
studies in the global literature with a total of 377,951 individuals, Allen and Robson (2020) concluded, bolstered by the relatively large sex moderation effect size, that homosexual men indeed scored higher in agreeableness than heterosexual men. Several studies have shown that women score lower in aggressiveness than men (Gladue \& Bailey, 1995) and higher in agreeableness than men (Lippa 2005, 2008; Greaves et al., 2017; Allen \& Robson, 2020). Empathic concern, the ability to sense feelings from (unfortunate) others, which in turn generates sympathy, compassion, and selfless concern for them, is also higher in homosexual than heterosexual men (Davis, 1983; Chee, Mohd Noor \& Ahmad, 2013). Social Dominance Orientation (SDO), which measures group-based social inequality and anti-egalitarianism, is lower in homosexual men than heterosexual men (Sidanius, Levin, Liu \& Pratto, 2000; Dickins \& Sergeant, 2008), and lower even than in heterosexual women (Dickins \& Sergeant, 2008).

Our interpretation is that men who exhibit MHP are more agreeable and empathetic to others, because they do not strive as much for dominance in a group, and hence present less of a threat to others. This, we believe, would increase effective team unity resulting in improved performance of groups or teams that contain homosexual men.

\section{Agreeableness, Cooperation and Team Performance}

\section{Agreeableness}

Agreeableness (as defined; see McCrae \& Costa (1997)), is described in many studies as capturing the following social conducts: accommodating, affectionate, affiliative, altruistic, attentive, caring, communal, communion striving, compassionate, compliant, conflict-resolving, considerate, cooperative, courteous, eager to help others, easy-going, emotionally supportive, empathic to others, fair, flexible, forgiving, frank, friendly, generous, gentle, good-natured, helpful, high care, humble, interpersonal harmony, 
kind, likable, like to work in a team, likely to be available when needed, low anger, nurturing, modest, moral, participative, peaceful, prosocial, reduce within-group competition, seeking social harmony, sincere, sharing, sociable, softhearted, straightforward, supportive, sympathetic, tender minded, tolerant, trusting, unselfish, and warm (McCrae \& Costa, 1985; McCrae \& John, 1992; Penner, Fritzsche, Craiger \& Freifeld, 1995; Barrick, Stewart, Neubert \& Mount, 1998; Feist, 1998; Costa Jr., Terracciano \& McCrae, 2001; Jawahar, 2002; Klein, Lim, Saltz \& Mayer, 2004; Barrick, Stewart \& Piotrowski, 2002; Peeters, Van Tuijl, Rutte \& Reymen, 2006; Graziano, Habashi, Sheese \& Tobin, 2007; Farooq, Khan \& Jibeen, 2016; Fleischman, Fessler \& Cholakians, 2015; Zhou, Hu \& Zey, 2015; Aeron \& Pathak, 2017; Hoch \& Dulebohn, 2017; Anderson, Keith, Francisco \& Fox, 2018; Coursey et al., 2018; Maranges \& Reynolds, 2017; O'Keefe et al., 2018; Aronson, Reilly \& Lynn, 2019). As Graziano et al. (2007) summarize, people with high agreeableness are more willing to help others, even in extraordinary circumstances such as saving the lives of strangers. This motivation is described as distinctly prosocial, because their helpful attitude towards strangers in stressful situations did not coincide with elevated personal distress for their own safety, but purely because of their empathetic concern for others. They offer help across a wide spectrum of social situations. Reminders by others to help in stressful situations did not further increase their already elevated helpfulness, suggesting that willingness to help is already at a high level and integral to having a more agreeable personality. Agreeableness is also positively correlated with high emotional intelligence (van der Linden et al., 2017). In team efforts, task cohesion, which reflects shared commitment to the team's task, was greater with increasing agreeableness averaged over all team members (Barrick et al., 1998; van Vianen \& De Dreu, 2001). 
Three components of agreeableness, namely altruism, empathy and nurturance, are highly genetically determined, with heritability estimates of $56 \%, 68 \%$ and $70 \%$, respectively in 573 twin pairs in Italy, Japan, Canada, and the United States of America (Rushton, Fulker, Neale, Nias \& Eysenck, 1986). Similar values were found in a study of agreeableness-related traits in 402 twins (Tellegen et al., 1988). Heritability of agreeableness among 807 pairs of twins varied between 51\% and 58\% (Loehlin, McCrae, Costa \& John, 1998). A heritability of $46 \%$ for agreeableness was found in a meta-analysis of 9440 pairs of twins across 50 years of relevant published research (Johnson, Vernon \& Feiler, 2008). Among 964 twins the additive genetic influence on agreeableness was $42 \%, 57 \%$ or $66 \%$, depending on analysis methodology (Riemann, Angleitner \& Strelau, 1997). In a meta-analysis of 62 independent primary personality studies, involving more than 100,000 individuals, agreeableness had a 35\% heritability estimate (Vukasović \& Bratko, 2015). Molecular studies have identified SNPs that are correlated with agreeableness (Bae et al., 2013).

\section{Cooperation}

Agreeableness predicts cooperative behavior (Barrick, Mitchell \& Stewart, 2003). In interpersonal conflict resolution, students high in agreeableness pursued more constructive tactics; negotiation, compromise, and working towards solutions through a collaborative approach. They even sometimes contributed to dropping the topic under discussion when the situation had become too contentious, avoiding conflict while at the same time maintaining social interaction (Jensen-Campbell \& Graziano, 2001; Forrester \& Tashchian, 2013). Those agreeable students considered destructive tactics such as physical action, threats, and undermining the other's self-esteem as especially inappropriate (Jensen-Campbell \& Graziano, 2001). Central positions in networks based on trust were occupied by individuals high in empathy, which is highly correlated with 
agreeableness (Morelli, Ong, Makati, Jackson \& Zaki, 2017). More agreeable people are more likeable, i.e. more popular with partners they interact with socially (Nikitin \& Freund, 2015). Highly agreeable people also tend to have more communication partners in their network (Gloor et al., 2011), and work to maintain and use such contacts (Wolff \& Kim, 2012). Such supportive ties within their networks are strong and involve a large diversity of connections (Rapp, Ingold \& Freitag, 2019).

Morgeson, Reider and Campion (2005) summarize why agreeable members are crucial to team or group success: they work cooperatively, are better able to resolve conflict, and are more likely to help others. High-agreeableness in some team members makes others feel comfortable; this facilitates supportive and collaborative within-team communication, leading to more effective decision making (Bradley, Baur, Banford \& Postlethwaite, 2013). Agreeableness helps to bring about the interpersonal interactions that a team needs in order to be successful, including its interactions with the outside world (Zhou et al., 2015). In a study of 340 French individuals in 34 teams in four sports (i.e., basketball, handball, rugby and volleyball), highly agreeable individuals tended to take up the role of non-verbal informal team leaders (Kim, Gardant, Bosselut \& Eys, 2018). Processes relevant to team-creativity, necessary for teams to reach their creative potential, are also facilitated by team members high in agreeableness (Taggar, 2002). People high in agreeableness tend to be more open to new ideas, facilitating creativity, cooperation, and social-emotional contributions to teamwork (Coursey et al., 2018).

After teams have worked together for several months, a phenomenon called “centrality" within a network can appear for some individual team members, even though they are not team leaders. A highly agreeable member can draw other members to them, with the expanded network giving the agreeable member benefits such as 
increased access to information and increased influence, which in turn benefits the team (Klein et al., 2004). In a study of 180 students, those with high agreeableness were especially good "boundary spanners", who network and link with others, providing new insights, advice and alliance options. As a result, these individuals also excelled in performance in course exams (Battistoni \& Fronzetti Colladon, 2014). Highly agreeable team members often assume centrality in friendship networks where other team members seek support and camaraderie (Klein et al., 2004). At a higher level, a superior team or group can itself take on a centrality role within a network of teams, providing access to unique knowledge and benefitting the team's task performance (Balkundi \& Harrison, 2006).

\section{Team performance}

Not only is cooperation between individuals increased with a highly agreeable person involved, but it also may translate into greater team performance. Agreeableness is particularly important in team settings, as it can predict performance (Stewart, 2003). High levels of agreeableness were associated with compliance with team goals, even if not directly relevant to the individual (van Vianen \& De Dreu, 2001). Agreeableness contributes to communal striving (Barrick et al., 2002), keeping the team together, getting along with one another, motivated and highly-functional, in effect facilitating others to focus on task-oriented goals that then lead to superior team performance. Agreeableness is the strongest predictor among the Big Five personality traits of team performance, partly through positively influencing team processes (Hoch \& Dulebohn, 2017). Highly agreeable team members are more willing to share information (de Vries, Bart \& de Ridder, 2006), which can be key to reaching joint goals and superior team performance. Within teams, Aeron and Pathak (2017) propose that high agreeableness will decrease relationship and task conflict, and consequently increase team 
performance. High agreeableness of team members increased cooperation and hence team performance in a study of 652 employees working in 51 diverse teams in assembly plants for small appliances, electronic equipment and rubber-manufacturing (Barrick et al., 1998). This is especially true when the success of the team as a whole is the aim, rather than being a successful individual team member in competition with other team members (Beersma et al., 2003). Higher agreeableness among more than 400 individuals in 47 military service teams resulted in greater team-level performance (Halfhill, Nielsen, Sundstrom \& Weilbaecher, 2005). A study of the literature on engineering design teams found that agreeableness was highly positively associated with improved team performance (Ogot \& Okudan, 2006). A meta-analysis of nine studies confirmed that higher agreeableness resulted in higher team performance, especially for experienced professional teams (Peeters et al., 2006). Agreeableness increases team cohesion over time, which results in superior team performance, based on studies of 80-140 teams (Bradley et al., 2013; Mathieu, Kukenberger, d'Innocenzo \& Reilly, 2015; Acton, 2016; Aronson et al., 2019).

Aronson et al. (2019) go further and propose that in today's globally competitive world, with its breakneck speed of innovation, the time to market from a product idea to its successful commercialization is decreased by having high agreeableness in teams, because internal frictions are minimized. Geographically dispersed virtual teams pose additional challenges in which cohesion will be crucial to performance, and highly agreeable members in teams enhance that cohesion. Even a single highly agreeable person in a team can increase social cohesion, decrease team conflict, and enhance collective cooperativeness, thus raising team performance. Such team-level influence makes it important to include at least one highly agreeable member in such teams (Stewart, Fulmer \& Barrick, 2005). Highly agreeable team members may also 
compensate for other lazy members, thus lifting team performance above expectations (Schippers, 2013).

Increasingly, the study of overall team performance is augmented with what a specific kind of team member adds to the team. There is renewed attention in the study of teams as networks of individuals, in which the network is not only greater than the sum of its parts, but also reflects that the behavior of individual members can spill over to other team members. Such spillovers may influence the thoughts and feelings of the others, which in turn can positively affect team behavior and performance. Norms set by influential team members, which are accepted by other team members, can persist for a long time in the improved team culture, even after the initiating team members have left (Emich \& Wright, 2016).

In various studies, expressed in somewhat varying terminologies, the consensus emerges that three behavioral patterns contribute to influence team performance: dominance or individual prominence; sociability or interpersonal affect, which includes agreeableness; and task orientation or group goal facilitation (Driskell, Driskell, Burke \& Salas, 2017). Driskell et al. (2017) identify 13 role model clusters, of which one is that of contributing a foremost "social role" within and to the team. This "social role" harmonizes, aids, supports, and reassures others by appeasing, resolving disputes, commending others, expressing warmth, emotion and solidarity, enhancing cohesiveness, and assisting morale. Furthermore, while the "social role" is instrumental to a team, if too many team members take on that role it may lead to redundancy and disharmony (Driskell et al., 2017). Team members with unique complementary qualifications are not just beneficial to the team, but the benefits of this complementarity may grow over time (Neffke, 2019). 


\section{From MHP, to Increased Agreeableness, to Increased Cooperation, to Increased Team Performance}

If MHP is indeed more common when individuals depend for their evolutionary fitness and survival on teamwork, this may be because on average, as reviewed above, men who manifest MHP also express increased agreeableness, more effective conflictresolution skills and greater encouragement of increased cooperation within their team. This may translate into superior performance by mixed teams that contain heterosexual and male homosexual members.

We suggest that one or a few team members who express an above-average level of agreeableness, linked to their MHP, may contribute significantly to calming and bringing together a larger mixed team. Translated into better team performance, this could also benefit the team's larger community, depending on the importance of the team to the evolutionary fitness and survival of that community. That in turn will lead to relatively greater access to resources, compared to other communities without men who express MHP, which culminates in greater reproductive success of the entire community, including the heritable portion of the mechanism that underpins MHP of some community members. Improved group performance will include enhanced reproduction of its genes, including genes for MHP in heterozygous carriers, thus explaining a portion of the prevalence of male homosexual preferences.

Note that the positive role of homosexuals we propose for the team does not require homosexual behavior among the mixed team members. Heterosexual team members need not all be heterozygous carriers or even be aware of homosexuals in their midst. The cooperation serves a purely social function that springs from reduced aggression within the team, which encourages the team's wellbeing and engenders an 
enhanced spirit of cooperation, to the extent of raising team performance relative to other teams not so enriched.

Once a team has been positively influenced in this way, new normative attitudes may spill over to other non-team members, as Emich and Wright (2016) have shown. This contrasts with some of the other proposed hypotheses, where benefits are strictly limited within the family or primary group. The spillover effect of the improved mixedteam performance hypothesis may well allow "initiated" team-members to become rolemodels outside the team where they first experienced improved mixed team performance. Norm formation towards increased cooperation has been shown to emerge as members of paired teams subsequently form new paired teams, especially on cooperative interpersonal challenges (Bettenhausen \& Murnighan, 1991). A single member with a cooperative orientation, based on previous experience, paired with a competitive partner, challenges the other more persuasively and positively, resulting in the pair jointly achieving the task in a more cooperative fashion than two competitive partners paired. Thus, others may benefit from experiencing better performance through enhanced cohesiveness and group cooperation, and this better performance may include greater reproductive success. We propose that groups that enjoy this beneficial effect of having one or more members with high agreeableness, such as members who exhibit MHP, can be made up of highly diverse members, including men and women, grownups and children, the elderly and the young, and can be a mix of any sexual orientation, behavior or preference.

We note that the literature on hypergyny and MHP indicates that MHP may be more prevalent in the higher strata of stratified societies (Barthes et al., 2015). We offer an alternative explanation for increased MHP presence in higher strata. Groups that are more cooperative and successful, due to the presence of some more agreeable MHP 
men, are exactly the ones that will gain in community appreciation and emulation, and thus reach the upper echelons of society. High social strata have fewer members, which would further facilitate low-frequency homosexuality-related positive forces that promote intra-group cooperation to increase performance. In our hypothesis, MHP has an active, direct, and positive function in mixed-team performance, and may even spill over to other social teams or groups. The hypergyny hypothesis, by contrast, sees male homosexuality as just a pleiotropic trait with a negative impact on reproduction and no direct adaptive value for the observed outcome of enhanced social stratification. MHP could have been any other trait hitching a ride in heterosexual heterozygotes.

The improved mixed-team performance hypothesis assigns a distinctly positive role to MHP-associated personality traits. We see MHP not as a fitness cost to the larger group and community, a behavior that one could reject, tolerate or accept, but rather as a cluster of behaviors that we should embrace as a true benefit to team functioning and performance.

A complex trait such as MHP will likely have several underpinning influences, which may include some of those described in other hypotheses. Nevertheless, we emphasize that successful improved mixed-team performance may substantially add to evolutionary fitness. The presence of MHP may therefore be a consequence of natural selection for successful human evolution.

\section{Implications}

Studies on homosexuality often suffer the potential bias of being based on self-reporting surveys, rather than more objective approaches. The question is how to move from evolutionary theorizing to arrive at hard, supportive empirical data that offer convincing evidence. 
We believe our hypothesis of improved mixed-team performance can be quite readily studied, quantified, and tested through direct studies of team cooperation and performance in settings where extensive multi-environment and multi-year quantitative performance data are collected. These might include, for example, competitive sport teams, survival games groups (popular on TV), corporate work groups, military groups, street gangs, musical ensembles, etc. One would need accurate, quantifiable data on gender, sexual preferences and personality measures for all team members, and on team performance. Several of these competitive settings take place at an international level with strict record-keeping, allowing comparisons within and across cultures. We suggest that such studies also use social network analysis together with classical comparative approaches, because traits expressed in a social environment influence other interacting individuals, resulting in dynamic feedback on the traits that affects the social community's evolution (Griffing, 1967; Fisher \& McAdam, 2017). Homophobia and related discriminatory behavior when evaluating teams should definitely be included as a covariant, for which the analysis can be corrected, so it does not distort, bias or confound the hypothesis we want to study. Similar to Barron's and Hare's (2020) sociosexual hypothesis, on which we build, which calls for studies to determine if MHP evolves as part of the selection for prosocial behavior, we encourage studies to see whether improved mixed-team performance does indeed ensue due to the membership of MHP individuals. Empirical studies should investigate whether the presence of homosexual men affects team performance in all-male and mixed teams. Women generally score higher on agreeableness than men in many studies (Costa et al., 2001; Lippa, 2008; Greaves et al., 2017; Allen \& Robson, 2020). Our proposal offers the hypothesis that even in teams with females, who tend to be more agreeable than men, the presence of homosexual men still adds value and further 
increases team performance. In conjunction, it could be studied how and why the contribution to team performance from agreeable homosexual men might differ from that of agreeable women. Time-line hypotheses can be studied, in which a team's performance is followed over time, as homosexual men are and are not members of the teams. In addition, it may be important to identify the kind of teams in which homosexual men may or may not make a difference in performance, which would depend on the specific team activity, such as playing music, competing in sports or executing military exercises.

Our proposal is based on how the inclusion of highly agreeable men who also exhibit MHP may help facilitate team cohesion and thus superior team performance in modern settings. We have presented only some of the evolutionary aspects of MHP in human societies as they combine to improve mixed-team performance, not the many and varied potential mechanisms of implementation of heritability across generations through nature and nurture, through genetic and cultural evolution, pleiotropically or not. It is premature to anticipate the exact underpinning and enabling process of this improved mixed-team performance, until it has been established to exist. We hope that this new angle on team cooperation and performance may generate predictions about possible chromosomal regions and other underpinning mechanisms of MHP and its presence in human populations. At present there seem insufficient data to determine the relative contributions of nature and nurture to the expression of MHP; our hypothesis does not depend on knowing their relative contributions, but it may open up new ways to study the question of relative importance within what Adriaens and De Block (2006) call an evolutionary social construction. If improved mixed-team performance is shown to indeed operate, then we can study the underpinning mechanisms. That would allow 
our proposal to be included among earlier hypotheses, which together would be better able to explain the full prevalence of MHP.

We hope that discussion of this new hypothesis will encourage social research and discourse on the positive influence that homosexual men can have in teams, groups and society as a whole. This is particularly important as society becomes more globalized, multi-layered and complex, and we increasingly look to highly-functional multi-component teams for local and global solutions.

Acknowledgements. We thank Dr Jeremy Cherfas for help preparing the manuscript.

\section{References}

Abild, M. L., VanderLaan, D. P., \& Vasey, P. L. (2014). Does geographic proximity influence the expression of avuncular tendencies in Canadian androphilic males? Journal of Cognition and Culture, 14, 41-63. doi:10.1163/15685373-12342109

Acton, B. P. (2016). Working in Harmony: The Impact of Personality on the Short- and Long-Run Dynamics of Team Cohesion. Master of Science in Psychology, Virginia Polytechnic Institute and State University.

Adriaens, P. R., \& De Block, A. (2006). The evolution of a social construction: The case of male homosexuality. Perspectives in Biology and Medicine, 49(4), 570585. doi:10.1353/pbm.2006.0051

Aeron, S., \& Pathak, S. (2017). Personality, conflict and performance: Exploring predictive relationships. IUP Journal of Organizational Behavior, 16(2), 35. Retrieved from https://www.iupindia.in/1704/Organizational\%20Behavior/Personality_Conflict _and_Performance_Exploring.html

Allen, M. S., \& Robson, D. A. (2020). Personality and sexual orientation: New data and meta-analysis. The Journal of Sex Research, 57(8), 953-965. doi:10.1080/00224499.2020.1768204 
Anderson, G., Keith, M. J., Francisco, J., \& Fox, S. (2018). The Effect of Software Team Personality Composition on Learning and Performance: Making the "Dream" Team. Proceedings from 51st Hawaii International Conference on System Sciences.

Aronson, Z. H., Reilly, R. R., \& Lynn, G. S. (2019). Understanding the role of team member personal style in project performance: Does the type of innovation matter? International Journal of Innovation and Technology Management, 16(04), 1940002. Retrieved from https://www.worldscientific.com/doi/abs/10.1142/S0219877019400029

Bae, H., Sebastiani, P., Sun, J., Andersen, S., Daw, E., Terracciano, A., ... Perls, T. (2013). Genome-wide association study of personality traits in the long life family study. Frontiers in Genetics, 4, 65. doi:10.3389/fgene.2013.00065

Bailey, J. M., Vasey, P. L., Diamond, L. M., Breedlove, S. M., Vilain, E., \& Epprecht, M. (2016). Sexual orientation, controversy, and science. Psychological Science in the Public Interest, 17(2), 45-101.

Bailey, J. M., \& Pillard, R. C. (1991). A genetic study of male sexual orientation. Archives of General Psychiatry, 48(12), 1089-1096. doi:10.1001/archpsyc.1991.01810360053008

Balkundi, P., \& Harrison, D. A. (2006). Ties, leaders, and time in teams: Strong inference about network structure's effects on team viability and performance. Academy of Management Journal, 49(1), 49-68. Retrieved from https://journals.aom.org/doi/abs/10.5465/amj.2006.20785500

Bao, A.-M., \& Swaab, D., F. (2010). Sex differences in the brain, behavior, and neuropsychiatric disorders. The Neuroscientist, 16(5), 550-565. doi:10.1177/1073858410377005

Barrick, M. R., Mitchell, T. R., \& Stewart, G. L. (2003). Situational and Motivational Influences on Trait Behavior Relationships. In M. R. Barrick \& A. M. Ryan (Eds.), Personality and Work: Reconsidering the role of personality in organizations (pp. 60-82). San Francisco: Jossey-Bass.

Barrick, M. R., Stewart, G. L., Neubert, M. J., \& Mount, M. K. (1998). Relating member ability and personality to work-team processes and team effectiveness. Journal of Applied Psychology, 83(3), 377. 
Barrick, M. R., Stewart, G. L., \& Piotrowski, M. (2002). Personality and job performance: Test of the mediating effects of motivation among sales representatives. Journal of Applied Psychology, 87(1), 43.

Barron, A. B., \& Hare, B. (2020). Prosociality and a sociosexual hypothesis for the evolution of same-sex attraction in humans. Frontiers in Psychology, 10, 2955. Retrieved from https://www.frontiersin.org/articles/10.3389/fpsyg.2019.02955/full

Barthes, J., Crochet, P.-A., \& Raymond, M. (2015). Male homosexual preference: Where, when, why? PLOS ONE, 10(8), 1-15. doi:10.1371/journal.pone.0134817

Barthes, J., Godelle, B., \& Raymond, M. (2013). Human social stratification and hypergyny: Toward an understanding of male homosexual preference. Evolution and Human Behavior, 34(3), 155-163.

Battistoni, E., \& Fronzetti Colladon, A. (2014). Personality correlates of key roles in informal advice networks. Learning and Individual Differences, 34, 63-69. doi: 10.1016/j.lindif.2014.05.007

Beersma, B., Hollenbeck, J. R., Humphrey, S. E., Moon, H., Conlon, D. E., \& Ilgen, D. R. (2003). Cooperation, competition, and team performance: Toward a contingency approach. Academy of Management Journal, 46(5), 572-590.

Bettenhausen, K. L., \& Murnighan, J. K. (1991). The development of an intragroup norm and the effects of interpersonal and structural challenges. Administrative Science Quarterly, 36, 20-35.

Blanchard, R. (2001). Fraternal birth order and the maternal immune hypothesis of male homosexuality. Hormones and Behavior, 40(2), 105-114. doi:10.1006/hbeh.2001.1681

Blanchard, R. (2018). Fraternal birth order, family size, and male homosexuality: Metaanalysis of studies spanning 25 years. Archives of Sexual Behavior, 47(1), 1-15. doi:10.1007/s10508-017-1007-4

Blanchard, R., \& Bogaert, A. F. (1996). Homosexuality in men and number of older brothers. American Journal of Psychiatry, 153(1), 27-31.

Blanchard, R., \& Bogaert, A. F. (2004). Proportion of homosexual men who owe their sexual orientation to fraternal birth order: An estimate based on two national probability samples. American Journal of Human Biology, 16(2), 151-157. doi:10.1002/ajhb.20006 
Bobrow, D., \& Bailey, J. M. (2001). Is male homosexuality maintained via kin selection? Evolution and Human Behavior, 22(5), 361-368. doi:10.1016/S10905138(01)00074-5

Bogaert, A. F., Skorska, M. N., Wang, C., Gabrie, J., MacNeil, A. J., Hoffarth, M. R., ... Blanchard, R. (2018). Male homosexuality and maternal immune responsivity to the y-linked protein nlgn4y. Proceedings of the National Academy of Sciences, 115(2), 302-306. Retrieved from https://www.pnas.org/content/115/2/302

Bradley, B. H., Baur, J. E., Banford, C. G., \& Postlethwaite, B. E. (2013). Team players and collective performance: How agreeableness affects team performance over time. Small Group Research, 44(6), 680-711.

Camperio Ciani, A., Cermelli, P., \& Zanzotto, G. (2008). Sexually antagonistic selection in human male homosexuality. PLoS One, 3(6), e2282. Retrieved from https://journals.plos.org/plosone/article?id=10.1371/journal.pone.0002282

Camperio Ciani, A., Corna, F., \& Capiluppi, C. (2004). Evidence for maternally inherited factors favouring male homosexuality and promoting female fecundity. Proceedings of the Royal Society of London Series B: Biological Sciences, 271(1554), 2217-2221. Retrieved from https://royalsocietypublishing.org/doi/10.1098/rspb.2004.2872

Camperio Ciani, A., \& Pellizzari, E. (2012). Fecundity of paternal and maternal nonparental female relatives of homosexual and heterosexual men. PLoS One, 7(12), e51088. Retrieved from 10.1371/journal.pone.0051088

Camperio Ciani, A., Battaglia, U., \& Zanzotto, G. (2015). Human homosexuality: A paradigmatic arena for sexually antagonistic selection? Cold Spring Harbor Perspectives in Biology, 7(4), a017657. Retrieved from https://cshperspectives.cshlp.org/content/7/4/a017657

Cantor, J. M., Blanchard, R., Paterson, A. D., \& Bogaert, A. F. (2002). How many gay men owe their sexual orientation to fraternal birth order? Archives of Sexual Behavior, 31(1), 63-71. doi:10.1023/A:1014031201935

Chaladze, G. (2016). Heterosexual male carriers could explain persistence of homosexuality in men: Individual-based simulations of an $\mathrm{x}$-linked inheritance model. Archives of Sexual Behavior, 45(7), 1705-1711. doi:10.1007/s10508016-0742-2 
Chee, C. S., Mohd Noor, A., \& Ahmad, A. (2013). Empathy and spirituality: Is there a gay advantage? International Journal of Psychology and Behavioral Sciences, 3, 18-22. Retrieved from http://article.sapub.org/10.5923.j.ijpbs.20130301.03.html

Costa Jr, P. T., \& McCrae, R. R. (1988). From catalog to classification: Murray's needs and the five-factor model. Journal of Personality and Social Psychology, 55(2), 258-265.

Costa Jr, P. T., Terracciano, A., \& McCrae, R. R. (2001). Gender differences in personality traits across cultures: Robust and surprising findings. Journal of personality and social psychology, 81(2), 322-331.

Coursey, L. E., Paulus, P. B., Williams, B. C., \& Kenworthy, J. B. (2018). The Role of Individual Differences in Group and Team Creativity Individual Creativity in the Workplace. In R. Reiter-Palmon, V. L. Kennel, \& J. C. Kaufman (Eds.), Explorations in Creativity Research (pp. 311-338). London: Academic Press. doi:10.1016/B978-0-12-813238-8.00014-0

Currin, J. M., Gibson, L., \& Hubach, R. D. (2015). Multidimensional assessment of sexual orientation and the fraternal birth order effect. Psychology of Sexual Orientation and Gender Diversity, 2, 113-122. Retrieved from https://psycnet.apa.org/doiLanding?doi=10.1037\%2Fsgd0000103

Davis, M. H. (1983). Measuring individual differences in empathy: Evidence for a multidimensional approach. Journal of personality and social psychology, 44(1), 113-126.

de Vries, R. E., Bart, V. D. H., \& de Ridder, J. A. (2006). Explaining knowledge sharing: The role of team communication styles, job satisfaction, and performance beliefs. Communication Research, 33(2), 115-135. doi:10.1177/0093650205285366

Dickins, T. E., \& Sergeant, M. J. T. (2008). Social dominance and sexual orientation. Journal of Evolutionary Psychology, 6(1), 57-71. Retrieved from https://akjournals.com/view/journals/1126/6/1/article-p57.xml

Driskell, T., Driskell, J. E., Burke, C. S., \& Salas, E. (2017). Team roles: A review and integration. Small Group Research, 48(4), 482-511.

Emich, K. J., \& Wright, T. A. (2016). The 'I's in team: The importance of individual members to team success. Organizational Dynamics, 45(1), 2-10. doi:10.1016/j.orgdyn.2015.12.001 
Farooq, F., Khan, M. A., \& Jibeen, T. (2016). Personality traits, religiosity and sensation seeking behavior among homosexual males. Pakistan Journal of Professional Psychologists, 6(1), 17-30.

Feist, G. J. (1998). A meta-analysis of personality in scientific and artistic creativity. Personality and Social Psychology Review, 2(4), 290-309.

Fisher, D. N., \& McAdam, A. G. (2017). Social traits, social networks and evolutionary biology. Journal of Evolutionary Biology, 30(12), 2088-2103. doi:10.1111/jeb.13195

Fleischman, D. S., Fessler, D. M. T., \& Cholakians, A. E. (2015). Testing the affiliation hypothesis of homoerotic motivation in humans: The effects of progesterone and priming. Archives of Sexual Behavior, 44(5), 1395-1404. doi:10.1007/s10508014-0436-6

Forrester, W. R., \& Tashchian, A. (2013). Effects of personality on conflict resolution in student teams: A structural equation modeling approach. Journal of College Teaching \& Learning, 10(1), 39-46.

Ganna, A., Verweij, K. J. H., Nivard, M. G., Maier, R., Wedow, R., Busch, A. S., ... Zietsch, B. P. (2019). Large-scale gwas reveals insights into the genetic architecture of same-sex sexual behavior. Science, 365(6456). doi:10.1126/science.aat7693

Gavrilets, S., Friberg, U., \& Rice, W. R. (2018). Understanding homosexuality: Moving on from patterns to mechanisms. Archives of Sexual Behavior, 47(1), 27-31. doi:10.1007/s10508-017-1092-4

Gladue, B. A., \& Bailey, J. M. (1995). Aggressiveness, competitiveness, and human sexual orientation. Psychoneuroendocrinology, 20(5), 475-485. doi:10.1016/0306-4530(94)00073-J

Gloor, P. A., Fischbach, K., Fuehres, H., Lassenius, C., Niinimäki, T., Olguin, D. O., ... Putzke, J. (2011). Towards "honest signals" of creativity - identifying personality characteristics through microscopic social network analysis. Procedia-Social and Behavioral Sciences, 26, 166-179. doi:10.1016/j.sbspro.2011.10.573

Graziano, W. G., Habashi, M. M., Sheese, B. E., \& Tobin, R. M. (2007). Agreeableness, empathy, and helping: A person $\times$ situation perspective. Journal of Personality and Social Psychology, 93(4), 583-599. Retrieved from https://psycnet.apa.org/record/2007-13393-006 
Greaves, L. M., Barlow, F. K., Huang, Y., Stronge, S., \& Sibley, C. G. (2017).

Personality across sexual identity and gender in a national probability sample in New Zealand. Sex Roles, 77(9), 653-662. doi:10.1007/s11199-017-0752-0

Griffing, B. (1967). Selection in reference to biological groups I. Individual and group selection applied to populations of unordered groups. Australian Journal of Biological Sciences, 20(1), 127-140.

Halfhill, T., Nielsen, T. M., Sundstrom, E., \& Weilbaecher, A. (2005). Group personality composition and performance in military service teams. Military Psychology, 17(1), 41-54. doi:10.1207/s15327876mp1701_4

Hamer, D. H. (1999). Genetics and male sexual orientation. Science, 285(5429), 803. doi:10.1126/science.285.5429.803a

Hamer, D. H., Hu, S., Magnuson, V. L., Hu, N., \& Pattatucci, A. M. (1993). A linkage between DNA markers on the $\mathrm{x}$ chromosome and male sexual orientation. Science, 261(5119), 321-327. doi:10.1126/science.8332896

Harris, C. M. (2004). Personality and sexual orientation. College Student Journal, 38(2), 207-212. Retrieved from https://go.gale.com/ps/anonymous?id=GALE\%7CA119741928

Hoch, J. E., \& Dulebohn, J. H. (2017). Team personality composition, emergent leadership and shared leadership in virtual teams: A theoretical framework. Human Resource Management Review, 27(4), 678-693. doi:10.1016/j.hrmr.2016.12.012

Jawahar, I. M. (2002). A model of organizational justice and workplace aggression. Journal of Management, 28(6), 811-834. doi:10.1177/014920630202800606

Jensen-Campbell, L. A., \& Graziano, W. G. (2001). Agreeableness as a moderator of interpersonal conflict. Journal of Personality, 69(2), 323-362. doi:10.1111/1467-6494.00148

Johnson, A. M., Vernon, P. A., \& Feiler, A. R. (2008). Behavioral Genetic Studies of Personality: An Introduction and Review of the Results of 50+ Years of Research. In G. J. Boyle, G. Matthews, \& D. H. Saklofske (Eds.), The SAGE Handbook of Personality Theory and Assessment: Volume 1 - Personality Theories and Models (pp. 145-173). London: SAGE Publications Ltd. doi:10.4135/9781849200462 
Kim, J., Gardant, D., Bosselut, G., \& Eys, M. (2018). Athlete personality characteristics and informal role occupancy in interdependent sport teams. Psychology of Sport and Exercise, 39, 193-203. doi:10.1016/j.psychsport.2018.07.011

Kirkpatrick, R. (2000). The evolution of human homosexual behavior. Current Anthropology, 41(3), 385-413. doi:10.1086/300145

Kishida, M., \& Rahman, Q. (2015). Fraternal birth order and extreme right-handedness as predictors of sexual orientation and gender nonconformity in men. Archives of Sexual Behavior, 44(5), 1493-1501. doi:10.1007/s10508-014-0474-0

Klein, K. J., Lim, B.-C., Saltz, J. L., \& Mayer, D. M. (2004). How do they get there? An examination of the antecedents of centrality in team networks. Academy of Management Journal, 47(6), 952-963. doi:10.5465/20159634

Lippa, R. A. (2005). Sexual orientation and personality. Annual Review of Sex Research, 16(1), 119-153. doi:10.1080/10532528.2005.10559831

Lippa, R. A. (2008). Sex differences and sexual orientation differences in personality: Findings from the BBC internet survey. Archives of Sexual Behavior, 37(1), 173-187. doi:10.1007/s10508-007-9267-z

Loehlin, J. C., McCrae, R. R., Costa, P. T., \& John, O. P. (1998). Heritabilities of common and measure-specific components of the big five personality factors. Journal of Research in Personality, 32(4), 431-453. doi:10.1006/jrpe.1998.2225

Maranges, H. M., \& Reynolds, T. A. (2017). Evolutionary theory of personality. In B. J. Carducci \& C. S. Nave (Eds.), The Wiley-Blackwell Encyclopedia of Personality and Individual Differences: Vol. I. Models and Theories (pp. 1-22). Hoboken, NJ: John Wiley \& Sons.

Mathieu, J. E., Kukenberger, M. R., d’Innocenzo, L., \& Reilly, G. (2015). Modeling reciprocal team cohesion--performance relationships, as impacted by shared leadership and members' competence. Journal of Applied Psychology, 100(3), 713-734.

McCrae, R. R., \& Costa Jr, P. T. (1997). Personality trait structure as a human universal. American Psychologist, 52(5), 509-516.

McCrae, R. R., \& Costa, P. T. (1985). Updating Norman's “adequacy taxonomy”: Intelligence and personality dimensions in natural language and in questionnaires. Journal of personality and social psychology, 49(3), 710-721. Retrieved from https://psycnet.apa.org/buy/1986-03750-001 
McCrae, R. R., \& John, O. P. (1992). An introduction to the five-factor model and its applications. Journal of Personality, 60(2), 175-215.

Miller, E. M. (1999). Homosexuality, birth order, and evolution: Towards a equilibrium reproductive economics of homosexuality; reproductive economics of homosexuality. Department of Economics and Finance Working Papers, 19912006, 19. Retrieved from https://scholarworks.uno.edu/econ_wp/19

Morelli, S. A., Ong, D. C., Makati, R., Jackson, M. O., \& Zaki, J. (2017). Empathy and well-being correlate with centrality in different social networks. Proceedings of the National Academy of Sciences, 114(37), 9843. doi:10.1073/pnas.1702155114

Morgeson, F. P., Reider, M. H., \& Campion, M. A. (2005). Selecting individuals in team settings: The importance of social skills, personality characteristics, and teamwork knowledge. Personnel Psychology, 58(3), 583-611.

Mustanski, B. S., DuPree, M. G., Nievergelt, C. M., Bocklandt, S., Schork, N. J., \& Hamer, D. H. (2005). A genomewide scan of male sexual orientation. Human Genetics, 116(4), 272-278. doi:10.1007/s00439-004-1241-4

Neffke, F. M. H. (2019). The value of complementary co-workers. Science Advances, 5(12), eaax3370. doi:10.1126/sciadv.aax3370

Ngun, T. C., \& Vilain, E. (2014). The Biological Basis of Human Sexual Orientation: Is There a Role for Epigenetics? In D. Yamamoto (Ed.), Epigenetic Shaping of Sociosexual Interactions (pp. 167-184). London: Academic Press. doi:10.1016/B978-0-12-800222-3.00008-5

Nikitin, J., \& Freund, A. M. (2015). The indirect nature of social motives: The relation of social approach and avoidance motives with likeability via extraversion and agreeableness. Journal of Personality, 83(1), 97-105.

O’Keefe, J., O’Keefe, E., \& Hodes, J. (2018). Evolutionary origins of homosexuality. The Gay and Lesbian Review Worldwide. Retrieved from https://glreview.org/article/evolutionary-origins-of-homosexuality/

Ogot, M., \& Okudan, G. E. (2006). The five-factor model personality assessment for improved student design team performance. European Journal of Engineering Education, 31(5), 517-529. doi:10.1080/03043790600797335

Peeters, M. A. G., Van Tuijl, H. F. J. M., Rutte, C. G., \& Reymen, I. M. M. J. (2006). Personality and team performance: A meta-analysis. European Journal of Personality, 20(5), 377-396. 
Penner, L. A., Fritzsche, B. A., Craiger, J. P., \& Freifeld, T. S. (1995). Measuring the prosocial personality. In C. Spielberger \& J. N. Butcher (Eds.), Advances in Personality Assessment, vol. 10 (pp. 147-164). Mahwah, NJ: Lawrence Erlbaum Associates, Inc.

Rahman, Q., \& Hull, M. S. (2005). An empirical test of the kin selection hypothesis for male homosexuality. Archives of Sexual Behavior, 34(4), 461-467. doi:10.1007/s10508-005-4345-6

Rahman, Q., \& Wilson, G. D. (2003). Born gay? The psychobiology of human sexual orientation. Personality and Individual Differences, 34(8), 1337-1382. doi:10.1016/S0191-8869(02)00140-X

Rahman, Q., Collins, A., Morrison, M., Orrells, J. C., Cadinouche, K., Greenfield, S., \& Begum, S. (2009). Maternal inheritance and familial fecundity factors in male homosexuality. Archives of Sexual Behavior, 38(1), 159-160. doi:10.1007/s10508-008-9456-4

Rapp, C., Ingold, K., \& Freitag, M. (2019). Personalized networks? How the big five personality traits influence the structure of egocentric networks. Social Science Research, 77, 148-160. doi:10.1016/j.ssresearch.2018.09.001

Rice, W. R., Friberg, U., \& Gavrilets, S. (2012). Homosexuality as a consequence of epigenetically canalized sexual development. The Quarterly Review of Biology, 87(4), 343-368. doi:10.1086/668167

Richters, J., Altman, D., Badcock, P. B., Smith, A. M. A., de Visser, R. O., Grulich, A. E., ... Simpson, J. M. (2014). Sexual identity, sexual attraction and sexual experience: The second Australian study of health and relationships. Sexual Health, 11(5), 451-460.

Riemann, R., Angleitner, A., \& Strelau, J. (1997). Genetic and environmental influences on personality: A study of twins reared together using the self- and peer report NEO-FFI scales. Journal of Personality, 65(3), 449-475. doi:10.1111/j.14676494.1997.tb00324.x

Rushton, J. P., Fulker, D. W., Neale, M. C., Nias, D. K. B., \& Eysenck, H. J. (1986). Altruism and aggression: The heritability of individual differences. Journal of personality and social psychology, 50(6), 1192-1198. Retrieved from https://psycnet.apa.org/record/1986-23787-001

Salais, D. A., \& Fischer, R. B. (1995). Sexual preference and altruism. Journal of Homosexuality, 28(1-2), 185-196. doi:10.1300/J082v28n01_10 
Sanders, A. R., Martin, E. R., Beecham, G. W., Guo, S., Dawood, K., Rieger, G., ... Bailey, J. M. (2015). Genome-wide scan demonstrates significant linkage for male sexual orientation. Psychological Medicine, 45(7), 1379-1388. doi: $10.1017 / \mathrm{S} 0033291714002451$

Sanders, A. R., Beecham, G. W., Guo, S., Dawood, K., Rieger, G., Badner, J. A., ... Collaboration, M. G. S. (2017). Genome-wide association study of male sexual orientation. Scientific Reports, 7(1), 16950. doi:10.1038/s41598-017-15736-4

Savolainen, V., \& Hodgson, J. A. (2016). Evolution of homosexuality. In T. K. Shackelford \& V. Weekes-Shackelford (Eds.), Encyclopedia of Evolutionary Psychological Science (pp. 1-8). Springer International Publishing. Retrieved from https://www.springer.com/gp/book/9783319196497

Schippers, M. C. (2013). Social loafing tendencies and team performance: The compensating effect of agreeableness and conscientiousness. Academy of Management Learning \& Education, 13(1), 62-81. doi:10.5465/amle.2012.0191

Sergeant, M. J. T., Dickins, T. E., Davies, M. N. O., \& Griffiths, M. D. (2006). Aggression, empathy and sexual orientation in males. Personality and Individual Differences, 40(3), 475-486. doi:10.1016/j.paid.2005.07.002

Sidanius, J., Levin, S., Liu, J., \& Pratto, F. (2000). Social dominance orientation, antiegalitarianism and the political psychology of gender: An extension and crosscultural replication. European Journal of Social Psychology, 30(1), 41-67. doi:10.1002/(SICI)1099-0992(200001/02)30:1<41::AID-EJSP976>3.0.CO;2-O

Stewart, G. L. (2003). Toward an understanding of the multilevel role of personality in teams. In M. R. Barrick \& A. M. Ryan (Eds.), Personality and Work: Reconsidering the role of personality in organizations (pp. 183-204). San Francisco: Jossey-Bass.

Stewart, G. L., Fulmer, I. S., \& Barrick, M. R. (2005). An exploration of member roles as a multilevel linking mechanism for individual traits and team outcomes. Personnel Psychology, 58(2), 343-365. doi:10.1111/j.1744-6570.2005.00480.x

Taggar, S. (2002). Individual creativity and group ability to utilize individual creative resources: A multilevel model. Academy of Management Journal, 45(2), 315330. doi: $10.5465 / 3069349$

Tellegen, A., Lykken, D. T., Bouchard, T. J., Wilcox, K. J., Segal, N. L., \& Rich, S. (1988). Personality similarity in twins reared apart and together. Journal of 
personality and social psychology, 54(6), 1031-1039. Retrieved from https://psycnet.apa.org/doiLanding?doi=10.1037\%2F0022-3514.54.6.1031 Tskhay, K. O., \& Rule, N. O. (2016). Ancient Homosexuality. In V. WeekesShackelford \& T. K. Shackelford (Eds.), Encyclopedia of Evolutionary Psychological Science (pp. 1-2). Cham: Springer International Publishing. doi:10.1007/978-3-319-16999-6_3376-1

van der Linden, D., Pekaar, K. A., Bakker, A. B., Schermer, J. A., Vernon, P. A., Dunkel, C. S., \& Petrides, K. V. (2017). Overlap between the general factor of personality and emotional intelligence: A meta-analysis. Psychological Bulletin, 143(1), 36-52. Retrieved from https://psycnet.apa.org/doiLanding?doi=10.1037\%2Fbul0000078

van Vianen, A. E. M., \& De Dreu, C. K. W. (2001). Personality in teams: Its relationship to social cohesion, task cohesion, and team performance. European Journal of Work and Organizational Psychology, 10(2), 97-120. doi:10.1080/13594320143000573

VanderLaan, D. P., Garfield, Z. H., Garfield, M. J., Leca, J.-B., Vasey, P. L., \& Hames, R. B. (2014). The "female fertility--social stratification--hypergyny" hypothesis of male homosexual preference: Factual, conceptual and methodological errors in Barthes et al. Evolution and Human Behavior, 35(5), 445-447.

Vasey, P. L. (2016). Homosexual behavior. In A. Fuentes (Ed.), The International Encyclopedia of Primatology (pp. 1-4). Wiley Online Library. Retrieved from https://onlinelibrary.wiley.com/doi/abs/10.1002/9781119179313.wbprim0180

Vukasović, T., \& Bratko, D. (2015). Heritability of personality: A meta-analysis of behavior genetic studies. Psychological Bulletin, 141(4), 769-785.

Wilson, E. O. (1975). Sociobiology: The new synthesis. Cambridge: Harvard University Press.

Wolff, H.-G., \& Kim, S. (2012). The relationship between networking behaviors and the big five personality dimensions. Career Development International, 17(1), 4366. Retrieved from https://www.emerald.com/insight/content/doi/10.1108/13620431211201328/full /html

Zhou, W., Hu, H., \& Zey, M. (2015). Team composition of new venture founding teams: Does personality matter? International Journal of Entrepreneurial Behavior \& Research, 21(5), 673-689. Retrieved from 
https://www.emerald.com/insight/content/doi/10.1108/IJEBR-04-20140072/full/html

Zietsch, B.P., Sidari, M.J., Abdellaoui, A., Robert Maier, Niklas Långström, Shengru Guo, Gary W. Beecham, Eden R. Martin, Alan R. Sanders and Karin J. H. Verweij. (2021). Genomic evidence consistent with antagonistic pleiotropy may help explain the evolutionary maintenance of same-sex sexual behaviour in humans. Nat Hum Behav 5, 1251-1258. https://doi.org/10.1038/s41562-02101168-8. 